\title{
KUALITAS PRODUK, HARGA DAN EKUITAS MEREK BERPENGARUH TERHADAP KEPUTUSAN PEMBELIAN DI J'CO DONUTS \& COFFEE METROPOLITAN MAL BEKASI
}

\author{
(QUALITY OF PRODUCTS, PRICES AND EQUITY OF BRANDS \\ AFFECTING THE DECISION OF PURCHASING IN J'CO DONUT $\mathcal{E}$ \\ COFFEE METROPOLITAN MAL BEKASI)
}

\author{
Oleh: \\ Anik Ariyanti ${ }^{1)}$, Rochmad Fadjar Darmanto ${ }^{2)}$ \\ Sekolah Tinggi Ilmu Ekonomi IPWI Jakarta1,2) \\ ariyanti.anik@yahoo.co.id1); rochmadfadjar@yahoo.co.id ${ }^{2)}$
}

Submit: 30 Nov 2019 Review: 18 Dec 2019 Accept: 24 Dec $2019 \quad$ Publish: Dec 2019

\begin{abstract}
Product quality, price and brand equity are factors that greatly influence consumer decision making for the purchase of a product or service. This study aims to determine the effect of product quality, price and brand equity on donut purchasing decisions at J.Co. Donuts $\mathcal{E}$ Coffee Metropolitan Mall Bekasi. The population in this study is the people of Bekasi City who make donut purchases in J.Co. Donuts $\mathcal{E}$ Coffee Metropolitan Bekasi Mall and samples were taken were 88 people. The results showed that product quality, price and brand equity partially and simultaneously had a positive and significant effect on donut purchasing decisions at J.Co. Donuts \& Coffee Metropolitan Mall Bekasi
\end{abstract}

Keywords:

Product quality, price and brand equity influence purchasing decisions.

\section{ABSTRAK}

Kualitas produk, harga dan ekuitas merek adalah faktor yang sangat berpengaruh terhadap pengambilan keputusan konsumen untuk pembelian produk atau jasa. Penelitian ini bertujuan untuk mengetahui pengaruh kualitas produk, harga dan ekuitas merek terhadap keputusan pembelian donut pada J.Co. Donuts \& Coffee Metropolitan Mal Bekasi. Populasi dalam penelitian ini adalah masyarakat Kota Bekasi yang melakukan pembelian donut di J.Co. Donuts \& Coffee Metropolitan Mal Bekasi dan sampel yang diambil sebesar 88 orang. Hasil penelitian menunjukkan bahwa kualitas produk, harga dan ekuitas merek secara parsial dan simultan berpengaruh positif dan signifikan terhadap keputusan pembelian donut di J.Co. Donuts \& Coffee Metropolitan Mal Bekasi.

Kata kunci:

Kualitas produk, harga dan ekuitas merek mempengaruhi keputusan pembelian 


\section{PENDAHULUAN}

Saat ini peminat donut di Indonesia mengalami peningkatan seiring juga semakin bertambahnya perusahaan donut yang menawarkan variasi rasa, bentuk dan harga. Persaingan yang semakin ketat ini mendorong setiap perusahaan donut untuk mengembangkan produknya agar lebih inovatif dan menarik minat pembeli. Perusahaan harus mampu memenuhi keinginan dan selera pembeli.

Demikian juga yang dilakukan oleh J.Co Donuts \& Coffee Metropolitan Mal Bekasi, bahwa kualitas produk menjadi prioritas utamanya. Memang dari harga, J.Co Donuts terkenal lebih mahal dari harga donut dari perusahaan lain seperti Dunkin Donuts misalnya. Namun, karena cita rasa yang khas, keunikan kemasan dan kualitas produknya yang lebih unggul, membuat pembeli tidak mempermasalahkan harga mahal dari donut di J.Co. Donuts \& Coffee Metropolitan Mal Bekasi. Hal ini dibuktikan dari panjangnya antrian pada saat proses pembelian.

Dari hasil pengamatan peneliti, faktor yang menjadi keunggulan dari J.Co Donuts \& Coffee Metropolitan Mal Bekasi ini adalah brand atau ekuitas merek yang sudah melekat di hati pelanggan pada umumnya. Dengan melihat logo J.Co Donuts, mereka sudah membayangkan lezat dan nikmat rasa donutnya. Pelanggan rata-rata puas setelah membeli J.Co Donuts \& Coffee Metropolitan Mal Bekasi. Mereka rela antri panjang untuk melakukan pembelian.

Hal inilah yang menarik peneliti, untuk melakukan penelitian lebih jauh tentang J.Co Donuts \& Coffee Metropolitan Mal Bekasi dari kualitas produk dan harga yang ditawarkan sehingga berpengaruh terhadap keputusan pembelian konsumen.

J.Co Donuts \& Coffee adalah salah satu restoran yang menawarkan sistem waralaba dan didirikan dan dimiliki oleh Johnny Andrean Group pada tahun 2005. Salah satu kekhasan dari donut J.Co adalah cita rasa yogurt beku dan kopi. Konsumen J.Co Donuts \& Coffee, merambah ke semua lapisan baik menengah ke atas juga menengah ke bawah. Walaupun J.Co Donuts \& Coffee mematok harga yang agak mahal namun ada promosi dengan sistem diskon untuk produk-produk tertentu. Selain itu, J.Co Donuts \& Coffee Metropolitan Mal Bekasi mempunyai ekuitas merek yang melekat yang menjadi kekuatan produknya.

\section{TUJUAN PENELITIAN}

Tujuan dari penelitian ini adalah untuk mengetahui pengaruh kualitas produk terhadap keputusan pembelian, pengaruh harga terhadap kualitas pembelian dan pengaruh ekuitas merek terhadap keputusan pembelian donut di J.Co Donuts \& Coffee Metropolitan Mal Bekasi.

\section{TELAAH LITERATUR DAN PENGEMBANGAN HIPOTESIS Kualitas Produk}

Produk adalah salah satu dari bauran pemasaran yang menduduki posisi pertama. Produk adalah barang/jasa yang ditawarkan kepada seseorang atau organisasi untuk memenuhi kebutuhan. Selain itu produk diciptakan untuk memenuhi keinginan konsumen.

Menciptakan produk yang berkualitas adalah salah satu upaya yang harus dilakukan oleh organisasi atau perusahaan agar konsumen puas mendapatkan produk yang diinginkannya. Kotler dan Amstrong (2012) berpendapat bahwa kualitas produk (product quality) adalah senjata strategi potensial yang digunakan untuk mengalahkan pesaing. Kualitas produk 
mampu menunjukkan ketahanan, kehandalan, ketepatan, kemudahan. Pendapat Kotler (2012) yang lain menjelaskan bahwa produk adalah segala sesuatu yang bisa ditawarkan ke pasar agar mendapat perhatian, dibeli, digunakan dan bisa dikonsumsi untuk dapat memuaskan keinginan dan kebutuhan konsumen.

Dalam penelitian yang dilakukan oleh Danny Kurniawan (2017) menyimpulkan bahwa kualitas produk memiliki pengaruh positif terhadap keputusan pembelian Sari Roti di Semarang. Semakin berkualitas produk yang ditawarkan, maka semakin tepat keputusan yang diambil konsumen untuk membeli Sari Roti di Semarang. Penelitian dari Mahyarani Tiara Ghassani (2017) berpendapat bahwa kualitas produk mempunyai pengaruh signifikan terhadap keputusan konsumen. Hasil penelitianya diketahui bahwa kepuasan produk yang disertai harga berpengaruh signifikan terhadap kepuasan konsumen. Semuanya ini memberikan bukti bahwa produk yang berkualitas adalah menjadi keinginan dan harapan setiap konsumen. Mereka akan selalu membeli produk yang menunjukan kualitasnya atau yang jelas-jelas berkualitas.

Kualitas produk adalah karakteristik produk yang bergantung atas kemampuannya memuaskan kebutuhan pelanggan. Menurut Lupiyoadi dan Hamdani (2009) bahwa dimensi kualitas produk meliputi kinerja, keragaman produk, keandalan, kesesuaian dan ketahanan atau daya tahan, kualitas pelayanan, estetika dan kualitas yang dipersepsikan.

\section{Harga}

Harga adalah nilai yang melekat pada barang/jasa yang berupa uang yang dikeluarkan pembeli untuk mendapatkan barang/jasa. Pengertian ini didasari oleh pendapat Amstrong (2016: 324) yang menjelaskan bahwa: "Prince the amount of money charged for a product or service, or the sum of the value that customers exchange for the benefits or having or using the product or service" artinya harga adalah sejumlah uang yang sengaja dikeluarkan untuk produk atau jasa. Dengan arti lain produk adalah sejumlah nilai yang ditukarkan konsumen untuk mendapat manfaat kepemilikan atau penggunaan sebuah produk atau jasa.

Dalam Wikipedia dijelaskan bahwa harga merupakan nilai tukar yang disamakan dengan uang atau barang lainnya untuk manfaat yang diperoleh dari suatu barang atau jasa bagi seseorang atau kelompok pada waktu dan tempat tertentu. M. Guntur (2010:281) berpendapat bahwa harga adalah sejumlah uang yang ditagihkan atas produk/jasa yang ditukarkan oleh pelanggan untuk memperoleh manfaat dan memiliki atau menggunakannya.

Penetapan harga yang tepat dan sesuai dengan keinginan konsumen tentunya akan menguntungkan kedua belah pilah baik perusahaan maupun konsumen. Seperti pendapat Kotler dan Keller (2016: 491) mengatakan bahwa tujuan penetapan harga adalah untuk kemampuan bertahan, laba maksimum saat ini, pangsa pasar maksimum, pemerahan pasar maksimum, kepemimpinan kualitas produk). Sedangkan Tjiptono (2012: 153-154) berpendapat berbeda bahwa tujuan penetapan harga adalah untuk mengenal permintaan produk dan persaingan, target pasar, marketing mix sebagai strategi, produk baru, reaksi pesaing, biaya produk dan perilaku biaya serta kebijakan yang ditentukan oleh pemerintah dan lingkungan.

Pada penelitian Yanuar Firmanto (2019) menyebutkan bahwa harga mempunyai pengaruh signifikan terhadap keputusan pembelian produk ayam goreng 
di Kentucky Fried Chicken (KFC), sheingga memberikan keyakinan bahwa harga yang ditawarkan KFC kepada konsumen berpengaruh signifikan terhadap keputusan pembelian konsumen.

\section{Ekuitas Merek}

Setiap produk yang dihasilkan oleh perusahaan diharapkan mempunyai nilai tambah dan mampu menumbuhkan rasa percaya diri konsumen untuk mengambil keputusan pembelian. Daryanto (2011) mengatakan bahwa ekuitas merek (brand equity) merupakan nilai suatu merek yang bersifat intangible. Dijelaskan pula oleh Daryanto bahwa mengelola ekuitas merek berpengaruh terhadap atribut keunggulan dalam bersaing.

Pendapat lain oleh Kotler dan Keller (2016: 344) menyebutkan bahwa ekuitas merek merupakan nilai tambah yang diberikan pada produk dan/atau jasa. Kottler beranggapan bahwa nilai tambah ini bisa dicerminkan dalam cara konsumen berfikir, merasa dan bertindak terhadap merek, harga, pangsa pasar, dan profitabilitas yang dimiliki oleh perusahaan.

Beberapa elemen dari ekuitas merek terdiri dari loyalitas merek, kesadaran merek, persepsi kualitas, asosiasi merek dan aset merek. Loyalitas merek adalah bentuk ukuran kesetiaan konsumen terhadap merek tertentu. Kesadaran merek adalah kemampuan konsumen mengenali atau mengingat kembali mengenai suatu merek yang merupakan bagian dari kategori produk. Asosiasi merek merupakan segala sesuatu terkait dengan memori terhadap sebuah merek produk. Persepsi kualitas adalah bentuk penilaian pelanggan terhadap seluruh kualitas/keunggulan produk.

Pada penelitian Rachel Dyah W dan Sarah Kimberlee (2019) mengatakan bahwa ekuitas merek dan keputusan pembelian mempunyai hubungan yang kuat dan positif, dan mempunyai pengaruh yang signfikan 56,7\% terhadap keputusan pembelian di Simetri Coffee Roasters Puri Kembangan. Dengan hasil ini dapat diketahui bahwa ekuitas merek menjadi pertimbangan konsumen dalam melakukan keputusan pembelian.

\section{Keputusan Pembelian}

Keputusan pembelian berkaitan dengan kebijakan dalam pengambilan keputusan untuk membeli suatu produk dan/atau jasa. Beberapa teori menyebutkan bahwa keputusan pembelian adalah suatu proses penyelesaian masalah dengan menganalisa serta pengenalan kebutuhan dan keinginan hingga perilaku setelah pembelian. Hal ini sesuai dengan pendapat Kotler dan Amstrong (2012) bahwa keputusan pembelian adalah tahap pada suatu proses pengambilan keputusan pembelian di mana konsumen benar-benar membeli produk. Assauri (2004) berpendapat bahwa keputusan pembelian adalah suatu proses pengambilan keputusan akan pembelian yang mencakup penentuan apa yang akan dibeli atau tidak melakukan pembelian dan keputusan ini diperoleh dari kegiatankegiatan sebelumnya.

Beberapa faktor lain yang mempengaruhi keputusan pembelian adalah faktor budaya, faktor sosial, faktor pribadi, dan faktor psikologis. Pendapat ini didukung pendapat Kotler dan Keller (2016:153) yang menjelaskan bahwa keputusan pembelian seseorang ditentukan oleh faktor psikologi yang berkaitan dengan persepsi serta keyakinan dan pendirian. Persepsi konsumen sangat berpengaruh terhadap pengambilan keputusan dalam pembelian.

Beberapa uraian di atas memberikan gambaran pemikiran dan hipotesis untuk penelitian ini, sebagai berikut: 
Gambar 1

Kerangka Pemikiran

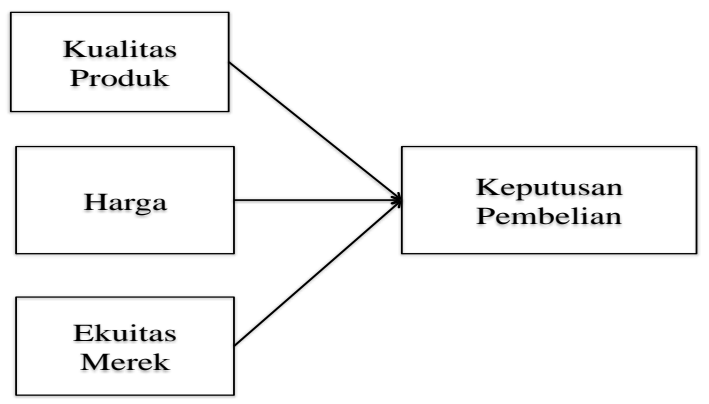

Sumber: data diolah 2019

\section{METODOLOGI PENELITIAN \\ Tempat dan Waktu Penelitian}

Penelitian ini mengambil objek penelitian di J.Co Donuts \& Coffee di Metropolitan Mal Bekasi Ground Floor di Jalan K.H. Noer Ali Kota Bekasi. Penelitian ini dilakukan selama 4 bulan dari JuliOktober 2019.

\section{Populasi dan Sampel}

Populasi dalam penelitian ini adalah masyarakat Kota Bekasi yang melakukan pembelian di J.Co Donuts \& Coffee Metropolitan Mal Bekasi di tahun 2018. Metode sampel dalam penelitian ini adalah purposive sampling. Dan penentuan jumlah sampel dengan menggunakan rumus Slovin dengan sampel sebanyak 88 orang.

\section{Desain Penelitian}

Penelitian ini adalah explanatory research atau jenis penelitian yang tujuannya untuk menjelaskan hubungan antara variabel-variabel dan menguji hipotesa. Penelitian ini menggunakan pendekatan kuantitatif. Variabel penelitian meliputi: variabel independen atau variabel bebas yaitu kualitas produk, harga dan ekuitas merek. Variabel dependen atau variabel terikat yaitu keputusan pembelian.

\section{Definisi Operasional}

Kualitas produk merupakan peryataan tentang tingkat kemampuan suatu merek atau produk tertentu dalam melaksanakan fungsi yang diharapkan (Assuari, 2015: 211)

Harga merupakan jumlah uang yang harus dibayar pelanggan untuk produk tertentu. Harga sangat membutuhkan pertimbangan yang sangat cermat karena harga merupakan a statement of value dan mempunyai peran utama dalam proses pengambilan keputusan (Kotler, 2012: 132).

Ekuitas merek adalah bentuk nilai tambah yang diberikan pada produk atau jasa yang dapat tercermin dari cara berfikir, merasa, dan bertindak yang berkaitan dengan merek (Kotler dan Keller, 2016)

Keputusan pembelian merupakan pemilihan dari dua atau lebih alternative pilihan keputusan pembelian. Hal ini berarti seseorang bisa membuat keputusan, harus tersedia beberapa alternative pilihan (Schiffman dan Kanuk, 2009: 112). Proses pembelian terdiri dari pengenalan masalah, pencarian informasi, evaluasi alternatif, keputuan pembelian dan perilaku pasca pembelian (Kotler, 2012).

\section{Pengumpulan Data}

Data yang diperoleh untuk penelitian ini adalah dari sumber data primer dan sekunder. Data primer berasal dari observasi dan penyebaran kuesioner kepada para konsumen di J.Co Donuts \& Coffee Metropolitan Mal Kota Bekasi. Adapun data sekunder diperoleh dari sumber lainnya yang mendukung penelitian ini yaitu dari buku, internet, jurnal, dan beberapa artikel.

\section{Uji Instrumen Penelitian}

Dengan uji validitas dan reliabilitas dapat mengetahui tingkat kevalidan dan kehandalan data penelitian. Uji validitas 
dapat diukur berdasarkan nilai Corrected Item-Total Correlation $>0,3$ yang berarti valid. Hasil pengujian membuktikan bahwa Seluruh pertanyaan Kualitas Produk (X1), Harga (X2) dan Ekuitas Merek (X3) serta Keputusan Pembelian (Y) dinyatakan valid dengan nilai Corrected Item-Total Correlation $>0,3$. Nilai Cronbach Alpha diketahui $>0,60$ artinya semua instrumen dari semua variabel terbukti reliabel.

\section{Metode Analisis}

Analisis data dalam penelitian ini menggunakan uji asumsi klasik melalui uji, multikolinieritas, heteroskedastisitas dan normalitas data. Selain itu dilakukan uji regresi linier berganda, koefisien determinasi dan uji hipotesis menggunakan program SPSS 16 for Windows.

\section{HASIL PENELITIAN DAN PEMBAHASAN \\ Hasil Penelitian Uji Asumsi Klasik}

Pada uji multikolinieritas diketahui nilai besarnya nilai tolerance untuk semua variabel bebas adalah sebesar 0,711 (X1), 0,671 (X2), 0,673 (X3)>10\% dan Variance Inflation Factor (VIF) masing-masing variabel independen 1,407 (X1), 1,491 (X2), dan $1,487<\mathrm{VIF}=10$ artinya antara variabel independen tidak terjadi multikolinieritas. Pada uji heteroskedastisitas dari grafik tergambar bahwa tidak ada pola yang jelas dan titik-titik menyebar di bawah serta di atas sumbu $\mathrm{Y}$, artinya tidak terjadi heteroskedastisitas. Pada uji normalitas diketahui bahwa grafik P-Plot yang dihasilkan menunjukkan tingkat normalitas data.

\section{Model Regresi Linier Berganda}

Pengujian ini dilakukan untuk mengetahui pengaruh kualitas produk, harga dan ekuitas merek terhadap keputusan pembelian pelanggan di J.Co Donuts \& Coffee Metropolitan Mal Bekasi. Hasilnya ujinya adalah sebagai berikut:

Tabel 1

Regresi Berganda

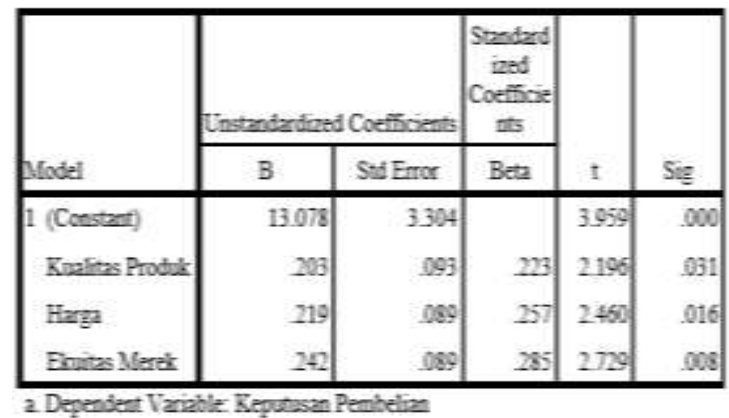

Sumber: Output SPSS

Tabel 1 tersebut menunjukkan model persamaan regresi:

$$
Y=13,078+0,203 X 1+0,219 \times 2+0,242 X 3 .
$$

Penjelasan dari hasil persamaan di atas memberikan bukti bahwa diketahui nilai konstanta Keputusan Pembelian (Y) sebesar 13,078 yang berarti bahwa jika nilai Kualitas Produk (X1), Harga (X2) dan Ekuitas Merek (X3) nilainya adalah 0, maka nilai $Y$ sebesar 13,078. Koefisien regresi masing-masing variabel independen bernilai positif, mengartikan bahwa keputusan pembelian J.Co Donuts \& Coffee Metropolitan Mal Bekasi dipengaruhi oleh kualitas produk sebesar 0,203, harga sebesar 0,219 dan ekuitas merek sebesar 0,242.

\section{Koefisien Determinasi}

Tabel 2

Koefisien Determinasi

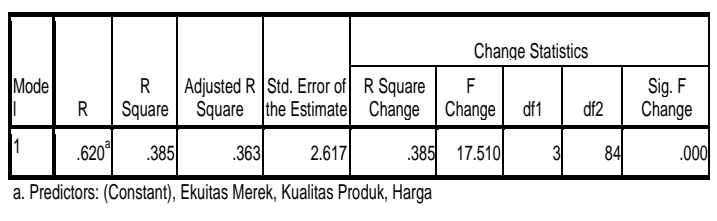

b. Dependent Variable: Keputusan Pembelian 
Tabel 2 membuktikan bahwa nilai koefisien determinasi yang dihasilkan sebesar 0,363 atau 36,3\% menunjukkan kualitas produk, harga serta ekuitas merek mampu menjelaskan keputusan pembelian J.Co Donuts \& Coffee Metropolitan Mal Bekasi, sedangkan 63,7\% dijelaskan dari variabel lain yang tidak diteliti.

\section{Pengujian Hipotesis}

Pada uji hipotesis diketahui nilai $t$ hitung dari variabel kualitas produk sebesar 2,196 dan nilai signifikan 0,031< dari alpha $(0,05)$, sehingga dapat diketahui bahwa kualitas produk mempunyai pengaruh positif dan signifikan terhadap keputusan pembelian. Nilai t hitung dari variabel harga sebesar 2,460 dan nilai signifikan 0,016 < dari alpha $(0,05)$, artinya harga mempunyai pengaruh positif dan signifikan terhadap keputusan pembelian. Nilai t hitung dari variabel ekuitas merek sebesar 2,729 dan nilai signifikan 0,008< dari alpha $(0,05)$, artinya ekuitas merek mempunyai pengaruh positif dan signifikan terhadap keputusan pembelian.

\section{Pembahasan}

Kualitas produk mempunyai pengaruh positif dan signifikan terhadap keputusan pembelian di J.Co Donuts \& Coffee Metropolitan Mal Bekasi. Hal ini dibuktikan pada nilai b1X1 sebesar 0,203 dengan signifikan sebesar 0,031<0,05.

Harga mempunyai pengaruh positif dan signifikan terhadap keputusan pembelian di J.Co Donuts \& Coffee Metropolitan Mal Bekasi. Hal ini dibuktikan pada nilai b2X2 sebesar 0,219 dengan signifikan sebesar 0,016<0,05.

Ekuitas merek mempunyai pengaruh positif dan signifikan terhadap keputusan pembelian di J.Co Donuts \& Coffee Metropolitan Mal Bekasi. Hal ini dibuktikan pada nilai b3X3 sebesar 0,242 dengan signifikan sebesar 0,008<0,05.
Hasil penelitian ini sesuai dengan penelitian yang dilakukan oleh Chanifah Widha Prihatini (2017) menunjukkan bahwa kualitas produk dan harga secara parsial dan simultan berpengaruh terhadap keputusan pembelian pada Warung Ikan Bakar Seafood Genteng Besar.

Penelitian lain menunjukkan hasil yang mendekati sama adalah penelitian oleh Josiel Driand Pandesolang dan Hendra N Tawas (2015) menyebutkan bahwa diferensiasi produk, kualitas produk dan ekuitas merek secara simultan berpengaruh signifikan terhadap keputusan pembelian, dan secara parsial diferensiasi produk berpengaruh positif signifikan terhadap keputusan pembelian, kualitas produk dan ekuitas merek secara parsial memiliki pengaruh tidak signifikan terhadap keputusan pembelian. Sebaiknya perusahaan tetap memperhatikan faktorfaktor diferensiasi produk, kualitas produk dan ekuitas merek. Khususnya meningkatkan faktor diferensiasi produk, melihat di ferensiasi produk berpengaruh positif serta memberikan kontribusi besar bagi keputusan pembelian.

\section{KESIMPULAN}

Kesimpulan dari penelitian ini dapat diuraikan sebagai berikut:

a. Kualitas produk berpengaruh positif dan signifikan terhadap keputusan pembelian di J.Co. Donuts \& Coffee Metropolitan Mal Bekasi.

b. Harga berpengaruh positif dan signifikan terhadap keputusan pembelian di J.Co. Donuts \& Coffee Metropolitan Mal Bekasi.

c. Ekuitas merek berpengaruh positif dan signifikan terhadap keputusan pembelian di J.Co. Donuts \& Coffee Metropolitan Mal Bekasi. 


\section{SARAN}

a. Kualitas produk perlu terus ditingkatkan dengan tetap mengutamakan cita rasa yang khas, kemasan yang inovatif dan variasi produk yang menarik minat pembeli.

b. Variasi harga perlu dipertahankan sehingga konsumen bisa membeli donut dengan memilih harga yang sesuai kantongnya.

c. Mempertahankan nilai tambah ini adalah keharusan bagi J.Co Donuts \& Coffee. Selain itu, juga harus tetap menjaga citra perusahaan dengan terus menumbuhkan kepercayaan masyarakat agar tetap menjadi pelanggan setia.

\section{DAFTAR PUSTAKA}

Assuari, Sofjan. (2015). Manajemen Pemasaran Dasar, Konsep dan Strategi. Jakarta: PT Raja Grafindo Persada.

Daryanto. (2011). Sari Kuliah Manajemen Pemasaran. Bandung: PT Sarana Tutorial Nurani Sejahtera.

Firmanto, Yanuar. (2019). Pengaruh Brand Image dan Harga terhadap Keputusan Pembelian Konsumen pada Produk Chicken di Kentucky Fried Chicken (KFC). Journal.unla.ac.id. Bandung: FE Langlangbuana

Ghassani, Mahyarani Tiara. (2017). Pengaruh Kualitas Produk dan Harga terhadap Minat Beli Ulang Bandeng Juwana Vaccum melalui Kepuasan Konsumen sbg Variabel Intervening (Studi Kasus Pelanggan PT. Bandeng Juwana Erlina Semarang. Diponegoro Journal of Social and Political Science. Semarang: Undip.
Guntur, Effendi M. (2010). Transformasi Manajemen Pemasaran. Jakarta: Sagung Seto.

Kotler, P dan Keller. (2016). Marketing Management, Edisi 14. New jersey: Prentice-Hall Published

Kotler, $P$ and Amstrong. (2012). Prinsipprinsip Pemasaran. Edisi ke-13 Jilid 1. Jakarta: Erlangga.

Kotler, P. (2012). Dasar-dasar Pemasaran, Edisi Keenam, terjemahan Wilhemnus W. Bokowatum. Jakarta: Intermedia.

Kurniawan, Danny dan Apriyanti. (2017). Analisis Pengaruh Harga dan Kualitas Produk terhadap Keputusan Pembelian Produk Sari Roti di Kota Semarang. Ejounal3-undip.ac.id. Semarang: Undip.

Lupiyoadi, R dan Hamdani, A. (2009). Manajemen Pemasaran Jasa. Jakarta: Salemba Empat.

Pandensolang, Josiel Driand dan Hendra N. Tawas. (2015). Pengaruh Deferensiasi, Kualitas Produk dan Ekuitas Merek terhadap Keputusan Pembelian Coca-Cola pada PT. Bangun Wenang Beverge Company di Manado. Jurnal Emba. ISSN 2303-11. Manado: Fak Ekonomi Unv.Sam Ratulangi.

Prihatini, Chanifah Widha dan Muhammad Edwar. (2014). Pengaruh Kualitas Produk dan Harga terhadap Keputusan Pembelian di Warung Ikan Bakar Seafood Genteng Besar. Jurnalmahasiswa.Unesa.ac.id. Surabaya: Unesa.

Schiffman dan Kanuk. (2008). Perilaku Konsumen. Edisi 7. Jakarta: Indeks.

Tjiptono, F. (2012). Strategi Pemasaran. Edisi Ketiga. Yogyakarta: Andi.

Wiastuti, Rachel Dyah dan Sarrah Kimberlee. (2018). Pengaruh Ekuitas Merek terhadap Keputusan Pembelian di Simetri Coffee Roaster Puri Jakarta. Jurnal Pariwisata. Jakarta: Binus. 